\title{
ENTREVISTA COM ENI ORLANDI
}

INTERVIEW WITH ENI ORLANDI

\author{
Eni Puccinelli Orlandi ${ }^{1}$, Maristela Cury Sarian ${ }^{2}$ \\ ${ }^{1}$ Universidade Estadual de Campinas (UNICAMP), Campinas, SP, Brasil \\ enip@uol.com.br \\ ${ }^{2}$ Universidade do Estado do Mato Grosso (UNEMAT), Cáceres, MT, Brasil \\ maristelasarian@unemat.br
}

Entrevista concedida em 16 dez. 2019

Maristela Sarian - Na obra A linguagem e seu funcionamento: as formas do discurso ${ }^{1}$, publicada pela primeira vez nos anos 80 , você apresenta a questão do discurso pedagógico autoritário em funcionamento no ensino brasileiro à época. Passados todos esses anos, essa noção também comparece no processo de compreensão de políticas públicas de ensino e instrumentos linguísticos do século $X X I$, sobretudo, no modo pelo qual se instituem sentidos para o ensino da língua brasileira e seus sujeitos na escola. Como você analisa esse funcionamento, nas condições de produção da contemporaneidade?

Eni Orlandi - Antes de tudo gostaria de fazer algumas observações sobre o que denominei discurso autoritário. Propus esta distinção exploratória porque parti da hipótese de que, em uma sociedade autoritária, não só o discurso do governo, mas também de suas instituições, estabelecem um discurso predominantemente autoritário. Com isso, objetivava fazer a crítica a nossa própria práxis institucional, a do conhecimento, preferencialmente à do discurso pedagógico. Quanto à denominação "autoritário", ela só significa em relação às duas outras: polêmico e lúdico. Devo considerar algo muito relevante para a compreensão do que é um discurso autoritário.

Primeiramente, observando que não é um julgamento, nem tem o sentido moral. É uma caracterização feita através de critérios discursivos, imanentes. Tratase de caracterizar o discurso segundo:

a) a relação entre os sujeitos - se há reversibilidade entre o sujeito que diz e o que ouve;

b) a relação dos sujeitos com os sentidos - se há imposição do sentido de quem diz para quem ouve;

c) a relação do dizer com os processos de significação, na relação paráfrase/polissemia - se há possibilidade de múltiplos sentidos ou só de um sentido, o imposto, considerado "literal", e, finalmente;

\footnotetext{
${ }^{1}$ ORLANDI, E. P. A linguagem e seu funcionamento: as formas do discurso. São Paulo: Brasiliense, 1983.
} 
d) a relação dos sujeitos, no caso do ensino, com o objeto de conhecimento se ela é aberta ou fechada.

Diante desta caracterização, eu diria que - e esta é minha segunda observação - na permanência de uma sociedade em que funciona a dissimetria entre sujeitos, ou seja, a sociedade capitalista, há muita probabilidade do discurso pedagógico ser autoritário. Mas pode ser também polêmico, sendo, para isso, necessário que seus protagonistas tenham uma práxis não autoritária e estabeleçam espaços de conhecimento politicamente significados como espaços abertos.

$\mathrm{Na}$ relação de tensão que proponho entre paráfrase (o eixo da repetição) e polissemia (o eixo da diferença), o discurso autoritário tende para a repetição (monossemia) e o polêmico para a sustentação de uma relação entre a paráfrase e a polissemia, podendo os sentidos serem outros. Pelo funcionamento do discurso pedagógico contemporâneo, domina ainda o discurso da repetição (do mesmo), portanto, autoritário.

M. S. - Você tem apresentado uma distinção entre a formação e a capacitação no que tange à formação de professores. ${ }^{2}$. Nesse sentido, de que forma os pressupostos teóricos da Análise de Discurso podem contribuir para a proposição de uma política de formação para os profissionais de Letras, tanto em nível de graduação, passando pelas chamadas formações continuadas, ofertadas pelas Secretarias de Educação de estados e municípios, quanto no âmbito da pósgraduação?

E. O. - A distinção que faço entre formação e capacitação ${ }^{3}$ não significa como está significada a palavra formação em "formação continuada". Ao contrário, é uma noção que procurei formular para abrigar a possibilidade de se pensar em uma prática pedagógica de construção real de conhecimento, e não presa ao imaginário escolar já significado antes mesmo que se estabeleçam relações concretas com os alunos. A distinção básica é a que estabeleço entre a relação do ensino com a informação - capacitação - e com o conhecimento, com o saber - formação. $\mathrm{Na}$ capacitação, consumo e cidadania se conjugam.

$\mathrm{Na}$ conjuntura histórica atual, a alfabetização e o desenvolvimento se declinam, então, em "educação e mercado", em que o mercado exige a qualificação do trabalho, a qualificação do trabalhador: um país educado. Isto significa um país rico em que os cidadãos "educados" são capacitados para o trabalho e circulam como

${ }^{2}$ ORLANDI, E. P. Uma prática de ensino transversal. Língua e Instrumentos Linguísticos, Campinas, v. 29, p. 11-22, 2012.

${ }^{3}$ ORLANDI, E. P. Formação ou capacitação: duas formas de ligar sociedade e conhecimento. In: FERREIRA, E.; ORLANDI, E. (org.). Discursos sobre a inclusão. Niterói: Intertexto, 2014. p. 141186. 
consumidores de um mercado de trabalho qualificado; neste caso, o da capacitação, o denominador comum é o trabalho, e não o conhecimento. Basta a informação, o treinamento. $\mathrm{O}$ mercado funciona como uma premissa indefinida para se falar em "sustentabilidade".

Esta palavrinha traz em seu efeito de memória a de desenvolvimento, que é o que precisamos, segundo o discurso dominante em uma sociedade capitalista, sobretudo em países ditos pobres. A capacitação é a palavra presente constantemente na mídia, na fala de empresários, governantes e... na escola. De nosso ponto de vista, este funcionamento discursivo silencia a força da reivindicação social presente, no entanto, na palavra formação. Pensando politicamente, podemos dizer que a formação, e não a capacitação, pode produzir um aluno "não alienado". Retomo, aqui, o conceito de K. Marx $(1844)^{4}$, segundo o qual a alienação desenvolve-se quando o indivíduo não consegue discernir e reconhecer o conteúdo e o efeito de sua ação interventiva nas formas sociais.

A análise de discurso pode prover elementos para que a formação, e não a capacitação, seja incentivada como forma de relação com o conhecimento. Já porque suas reflexões juntam sujeito, língua, educação e formação social. Em minhas reflexões, uno a isto uma teorização do sujeito em que se tem os seus modos de individuação, produzidos pela articulação simbólico-política do Estado, através de instituições e discursos. Aí incluo, nesta presente reflexão, a escola e os discursos do conhecimento.

Consideramos que a educação, e, em particular, o ensino da língua, como parte do que tenho trabalhado como a individuação do sujeito, neste caso, sendo a instituição a escola, poderia, se bem praticado como processo formador do indivíduo na sua relação com o social e o trabalho, dar condições para que este sujeito "soubesse" que sabe a língua e soubesse "ler e escrever", de forma a, em sua compreensão, ser capaz de dimensionar o efeito de sua intervenção nas formas sociais, com todas as consequência sociais e históricas que isto implica. Em uma palavra, se desalienasse. O que a capacitação não faz, pois o torna apenas um indivíduo bem treinado e, logo, mais produtivo. Isto não o qualifica em seu conhecimento, o que, com a formação, se dá e produz o efeito de tornar esse sujeito mais independente, deixando de ser só mais um instrumento na feitura de um "país rico". Ele estaria formado para dar mais um passo na direção de não só formular

\footnotetext{
${ }^{4}$ MARX, K. Manuscritos econômico-filosóficos. Rio de Janeiro: Boitempo, 2004. Originalmente publicado em 1844.
} 
como reformular e ressignificar sua relação com a língua institucionalizada, a da escola, mas também com a sociedade.

Ao invés de ser apenas um autômato de uma empresa (com a capacitação), poderia ser um sujeito em posição de transformar seu próprio conhecimento, compreender suas condições de existência na sociedade e resistir ao que o nega enquanto sujeito social e histórico. Tudo isto, se pensamos na formação - desde a educação básica, como o ensino superior - leva-nos a dizer que há modos de formar sujeitos preparados para descobertas e para inovações. Sujeitos bem formados que podem "pensar por si mesmos", tocando o real da língua em seu funcionamento e o da história, no confronto com o imaginário que o determina.

M. S. - Em Cidade dos sentidos, você afirma: "As relações de sentido materializadas pela Escola dão indicações de como, em sua textualização, ela significa o urbano. Que textualizações são essas? As que se praticam na escola - textos normativos como dicionários, gramática, dizeres sobre o conhecimento, organização da relação com a língua e com os sentidos, com os objetos de conhecimento, com as tecnologias - e as que, pela prática escolar, trazem o simbólico da rua pra dentro da escola" (ORLANDI, 2004, p. 152)5. Estabelecendo uma relação entre essas textualizações e as injunções postas para a escola do século XXI, de que maneira 0 ensino de línguas pode ser politicamente significado?

E. O. - Vivemos em uma sociedade em que o social é sobredeterminado pelo urbano, pela urbanidade. Nesta perspectiva, o social e o urbano se identificam e o espaço social, enquanto espaço de urbanidade, demanda formas de conhecimento que são significadas pela maneira como a sociedade toma corpo nesse espaço. Isto não significa que, empiricamente, não haja uma divisão entre o rural e o urbano. Isto significa que os processos de significação urbanos se estendem também para o espaço (físico) rural. Ele não fica fora, pois o que está dominando, na contemporaneidade, é o espaço material, simbólico, urbano.

A cidade, na perspectiva discursiva, é pensada, administrativamente, como espaço social hierarquizado e, na ordem do político, é tomada como território da civilidade. Pensando-se a Escola, face à sua organização social, na dimensão político-administrativa, ela produz ou mantém a dissimetria social, em sua verticalidade (hierarquização). Dificilmente rompe com este seu estatuto. A Escola é uma instituição decisiva na difusão dos processos de constituição do sujeito ocidental, cristão, letrado, ou seja, da forma sujeito histórica, capitalista e provê a sociedade de seus instrumentos necessários, inclusive linguísticos. Nosso espaço social/urbano manifesta uma saturação da linguagem e, em particular, do escrito,

${ }^{5}$ ORLANDI, E. P. Cidade dos sentidos. Campinas: Pontes, 2004. 
demandando sujeitos alfabetizados, escolarizados. Paredes, indicações de trânsito, avisos, nomes de ruas, nomes de lojas, títulos etc. habitam este espaço à exaustão. Entre eles também os que não são legitimados pela escola, mas são visíveis e marcam a presença de sujeitos existindo, apesar de não legitimados em suas formas de simbolização: pichação, grafite etc. Propagandas, exibidas até o horizonte de nossa capacidade de ver/ler, estão expostas no espaço público.

Para além dessas observações, podemos dizer que o espaço urbano também é espaço de uma pluralidade de línguas, em geral, com a dominante do inglês. $\mathrm{Na}$ rua, também outras formas materiais de linguagem se apresentam: imagens, sons, jogos, artefatos que significam. Portanto, estamos mergulhados em linguagem, com ou sem consciência disso. Não há urbanidade moderna sem escrita. A modernidade é feita desta relação Estado/Ciência/Escrita.

Quanto à escrita, por seu lado, também tem servido, na Escola, para verticalizar (hierarquizar) relações de contiguidade (diferença). Isto pode ser transformado pela formação, pois a escrita tem sua materialidade, e, em sua materialidade, a escrita pode ser tomada como um dos instrumentos pedagógicos que pode restituir o espaço simbólico da conviviabilidade, criando condições para as contradições, apontando, em sua práxis, para este jogo do vertical e do contíguo. A relação com a escrita - e com a leitura - deve ir além de se saber a língua e se saber que se a sabe. Mais relevante é saber como a língua está presente nas diferentes formas de linguagem. Incluindo-se à escrita escolar, pedagógica, também as manifestações linguageiras em geral, como as da rua. Não só pela sua "variedade", mas pelo seu funcionamento, que é político e simbólico.

Nesse sentido, o colocar-se a Escola em seu meio simbólico específico, que é a cidade, nos dá um observatório do político e do social, produzindo uma prática pedagógica propícia, que se relaciona com o real da rua, com outros modos de existência do sujeito social. Como afirmei em Cidade dos sentidos, a educação implica em processos, em percursos. E o que lhe está mais próximo é o que atravessa a cidade. Para isso, a escola tem de ir para a rua. Como sabemos, as políticas urbanas se textualizam, sob o modo de uma memória documental administrativa, jurídica, pedagógica etc., adquirindo um sentido particular. A Escola tem seu lugar nesse processo de textualização que, materializado, significa o social ao significar a rua. Não para simplesmente se instalar nela, mas para poder textualizar/metaforizar os sentidos que têm produzido. 
Proponho aqui a metaforização, não como já dito em Lacan e retomado por Pêcheux $(1975)^{6}$ - "uma palavra por outra" -, mas tomo a metaforização como modo de fazer com que, no discurso pedagógico, palavras falem com (outras) palavras e que sentidos se relacionem uns com os outros, na contiguidade e na diferença. Para que os sentidos sigam seus trajetos, irrompam, mudem, fujam. Se, no século $X X$, se pretendia, para uma boa formação, que a Escola trouxesse, para as salas de aula, "o mundo lá fora", a rua, hoje esse sentido se inverte. E digo sentido, não só significando direção, mas, sobretudo, uma abertura para sua liberdade e suas possibilidades de rupturas. A Escola na rua deixaria de ter como princípio organizador, pelas políticas públicas, ela mesma, e voltar-se-ia para a sociedade na história, ou seja, se socializaria. E o seu aluno, expondo-se a essas condições, iria historicizar seu processo de conhecimento.

M. S. - À moda de um ça circule, como um sentido evidente dominante, se diz que o aluno de hoje, sobretudo o da escola pública brasileira, não lê e não escreve, ou, ainda, não gosta de ler e de escrever. Como efeito dessas discursividades, produzse uma relação inequívoca entre leitura, escrita e aprendizagem. No que diz respeito ao ensino da leitura e da escrita na educação básica, de que modo as noções de língua, discurso e texto, filiadas à perspectiva materialista da Análise de Discurso, podem promover a desestabilização desses sentidos?

E. O. - A afirmação estereotipada de que o aluno de hoje não lê e não escreve significa mais a ignorância e falta de formação em estudos da linguagem de quem diz do que sobre quem se diz. A maneira como a análise de discurso concebe a língua e os sujeitos pode trazer uma compreensão mais interessante dessa questão, colocando-a em outras bases. Nunca se leu e se escreveu tanto. A língua, para o analista de discurso, não é um sistema perfeito, nem fechado em si mesmo. É da ordem da língua o não fechamento e a falha. Desse modo, para significar é preciso inscrever a língua na história. Se pensarmos a resistência e a individuação do sujeito pelo Estado, podemos avançar nessas considerações sobre leitura, escrita e língua. Para pensar a língua, podemos tomar a interpelação do indivíduo em sujeito pela ideologia, podendo, assim, dizer que, na figura da interpelação, estão criticadas duas formas de evidência: a da constituição do sujeito (como origem de si mesmo) e a do sentido (resultado da transparência da linguagem e igual a si mesmo, evidente). Esta é a crítica que fazemos à filosofia idealista da linguagem e à teoria subjetivista, através da teoria materialista do discurso.

${ }^{6}$ PECHÊUX, M. Les vérités de La Palice. Paris: Maspero, 1975. 
Para a análise de discurso, nem a língua é transparente nem o sujeito é sua própria origem, pois o sujeito se submete à língua mergulhado em sua experiência de mundo e determinado pela injunção de dar sentido, a significar-se. E o faz em um movimento sócio-historicamente situado, em que se reflete sua interpelação ideológica. Por isso, a relação com a escrita e a leitura não pode ser considerada de forma voluntarista. Nos gestos de leitura e de escrita entram determinações históricas e ideológicas. São estas que devemos aprender a mobilizar em nossas escutas, como formadores de conhecimento, e em nossos processos de ensino. $\mathrm{E}$ não dividir e excluir.

Dessa perspectiva discursiva, vivemos em uma sociedade em que ler e escrever adquirem muitas formas e sentidos. Um texto sustenta diversos gestos de interpretação; são muitas as possibilidades de leitura de um mesmo texto. Porque em um texto há múltiplos discursos trabalhando sua textualidade. São muitas as suas versões. Isto é o que chamamos historicidade da leitura que se mostra em diferentes gestos de interpretação. Por seu lado, sabemos discursivamente que a escrita adquire formas que vão além das letras aprendidas no ensino oficial legitimado e se espraia pelo espaço (urbano) social em suas múltiplas formas: digital, grafismo, em muitos e diferentes materiais simbólicos. $E$ isto é fundamental para que os sujeitos se simbolizem, pela escrita, tenha ela a forma que tiver.

A escrita escolar não pode assim desconhecer essas formas do sujeito identificar-se como ser simbólico e histórico. À Escola cabe dar conhecimento destas formas ao lado da forma oficial da letra e da leitura. A leitura, por sua vez, deve incluir uma práxis interpretativa para a compreensão dos diferentes materiais simbólicos que se apresentam na contemporaneidade. Há diferentes discursos, há a textualização de múltiplos discursos, em diferentes materialidades, em uma mesma língua. Isto deve ser objeto da formação produzida pela Escola atual, para alargar sua compreensão e suas possibilidades de escrita e de leitura. Quanto às tecnologias digitais, hoje, elas ocupam um campo particular e importante da nossa relação com a linguagem, seja escrita, seja oral.

M. S. - Pela produção de um efeito de evidência, as tecnologias digitais, regularmente filiadas ao sentido de metodologia, são materializadas nas políticas públicas de inclusão como a "saída" para os "problemas" do ensino brasileiro. E, ao silenciarem o processo histórico da escolarização no Brasil, essa compreensão faz irromper um sentido para o nosso ensino, sobretudo público, ancorado na discursividade do "fracasso". Como a Análise de Discurso poderia lançar luz a essas questões? 
E. O. - Voltemos à reflexão sobre conhecimento e informação para pensarmos o ensino e a sociedade contemporâneos. Na sociedade atual, a noção de cidadania liga-se à de consumidor e a educação relaciona-se a emprego, juntando mercado e trabalho, como dissemos. O conhecimento, assim significado em relação ao emprego, coloca a Educação na perspectiva do "humanismo reformista", definindose como uma questão de desenvolvimento e de demanda de informação para o trabalho. Espera-se que o Estado contribua na educação social, no entanto, há falta de projetos, de investimentos reais e suficientes para atingir este fim.

Neste sentido, podemos dizer que o Estado falha, produzindo a falta, que estigmatiza os sujeitos que não são escolarizados, não são "alfabetizados". A esta falta vincula-se a questão de cidadania ${ }^{7}$. O digital aparece, nessa perspectiva, como um artefato poderoso para se atingir estes resultados. Não se coloca a questão da Educação como uma questão de estrutura a ser transformada. Ela se reduz, assim, na ideologia reformista, como uma questão de capacitação, de treinamento. O digital é visto utilitariamente como instrumento para a aceleração desse processo, pois não resulta, como dissemos, na educação social em seu sentido mais forte, o de formação, definidor da busca de outra estrutura política, de outra formação social ${ }^{8}$.

Nessa direção, nossa posição é a de que o digital poderia ser significado para além de sua dimensão pragmática. No entanto, convivendo com o digital como instrumento de uma tecnologia, a educação tende a servir ao desenvolvimento, ao mercado. Desse modo, não se educa para a inserção social do sujeito em um mundo do conhecimento, mas capacita-se, como dissemos, esse sujeito, pela informação, e o digital é muito propício a este investimento, ou seja, para produzir e se servir da quantidade de informação.

Podemos mesmo afirmar que, na contemporaneidade, a materialidade específica da conjuntura da produção dos discursos, ou do desdobramento das discursividades, funciona pelo digital. Na falha do Estado em gerir, na educação, a presença e o trabalho do digital - que se apresenta, na maior parte das vezes pela falta do equipamento digital, o computador, como se este fosse a garantia da modernidade técnica - o imaginário da "aquisição" da cidadania se veste da falta do "digital". No entanto, na atualidade, o digital tem dimensão social presente na

\footnotetext{
${ }^{7}$ Do ponto de vista da análise de discurso, somos cidadãos, de direito, pois nascemos em uma República, mas, em sociedades não desenvolvidas, e extremamente dominadas pelas dissimetrias, a cidadania torna-se um bem disputado e ao qual os sujeitos só têm acesso a partir de certo número de apropriações.

${ }^{8}$ ORLANDI, E. P. Formação ou capacitação: duas formas de ligar sociedade e conhecimento. In: FERREIRA, E.; ORLANDI, E. (org.). Discursos sobre a inclusão. Niterói: Intertexto, 2014. p. 141186.
} 
simbolização dos sujeitos e na produção dos sentidos, em geral. Este é um equívoco que alimenta a ideia de fracasso e de exclusão, na educação social.

A meu ver, e como tenho repetido em minhas reflexões, o que nos falta não são equipamentos, mas condições que produzam espaços de conhecimento politicamente significados pela formação. Se consideramos que o digital constituiria, hoje, a condição de existência das discursividades, não se trata apenas de se ter acesso aos instrumentos e a informações, apagando o histórico, o social e o político, silenciando o equívoco que só a relação do simbólico com a ideologia pode fazer funcionar.

Podemos ter um exemplo na imprensa: esta foi uma condição, em um momento desse processo, ou seja, a imprensa se colocou como condição de existência e de desdobramento das discursividades, no momento de sua descoberta, afetando a relação com a escrita, a historicidade, a materialidade verbal e, logo, a posição-autor e o efeito-leitor. Para citar apenas um efeito material da imprensa, podemos lembrar que a autoria, antes resultado de cópias à mão, passa a ser feita por esteriotipo, em que a reprodução do mesmo alarga-se e muda seu modo de circulação e, consequentemente, a posição-sujeito autor e o efeito leitor. Assim como, na atualidade, a relação do digital com a informação é um fato de quantidade $^{9}$. Mas a imprensa afeta de maneira diferente da que se faz com o digital, embora tanto a imprensa como o digital atinjam a divisão do trabalho da escrita e da leitura, do trabalho intelectual.

Por isso, devemos repensar, contemporaneamente, a mídia, a comunicação, os sistemas de informação, refletindo sobre estes processos, na Escola: quantidade, reprodução. $E$ isso se faz buscando a compreensão da ordem do digital na relação dos sujeitos com os processos de significação, na presente conjuntura sóciohistórica, política e ideológica contemporânea. O que nos faz afirmar que não é o acesso a computadores que define o conhecimento como contemporâneo, mas a inserção do digital nas práticas sociais. Com efeito, é pensando as tecnologias na produção de um acontecimento nas relações sociais, uma alteração na formação social, que se podem pensar deslizamentos significativos que aí são produzidos, a partir da Escola, que demanda novos modos de reflexão, novas questões, outros modos de relações sociais na produção e circulação do conhecimento.

\footnotetext{
${ }^{9}$ Tenho observado, ao longo de minhas pesquisas sobre a cidade, que a questão da quantidade envolve sempre aspectos importantes relativos à circulação de sujeitos e sentidos, com consequências para o processo de significação, para a posição-sujeito, seja em outras condições, seja na condição autor ou do efeito leitor. $E$ isto tanto mais se apresenta quando se pensa o digital em sua materialidade, na relação com a Escola e o conhecimento.
} 


\section{Sobre a entrevistada}

\section{Eni Puccinelli Orlandi}

É pesquisadora do Laboratório de Estudos Urbanos da Unicamp e professora colaboradora do IEL da Universidade Estadual de Campinas. Atualmente é professora visitante da UNEMAT, atuando no ProfLetras e no Programa de Pós-Graduação em Linguística. Atua principalmente nos seguintes temas: análise de discurso, linguística, epistemologia da linguagem, história das ideias linguísticas, história das ideias discursivas, e jornalismo científico. É pesquisadora $1 \mathrm{~A}$ do $\mathrm{CNPq}$.

\section{Sobre a entrevistadora}

\section{Maristela Cury Sarian}

É graduada em Letras-Tradutor e Mestre em Estudos Linguísticos pela UNESP/São José do Rio Preto. Doutora em Linguística pela UNICAMP, é professora da Universidade do Estado de Mato Grosso (UNEMAT) Carlos Alberto Reyes Maldonado. Na gestão, atua como Coordenadora do Programa de Mestrado Profissional em Letras - PROFLETRAS ofertado na Unidade Cáceres. Como destaque na pesquisa, coordena, com Claudia Regina Castellanos Pfeiffer (LABEURB/UNICAMP) e Ana Cláudia Fernandes Ferreira (IEL/UNICAMP), a Linha 1 - História das Ideias Linguísticas - do GTAD da ANPOLL. Tem experiência na área de Letras, com ênfase em Linguística Língua Portuguesa e Estudos da Tradução. 